\title{
The Applied Research and Practice of Flipping Classroom Teaching Mode of College English Majors
}

\author{
Dan Guo \\ School of Foreign Languages, Anshan Normal University \\ Anshan, China \\ Email: guodanxuri@126.com
}

\begin{abstract}
On the basis of retaining the internalization and discussion of the two teaching links, the research combines the flipping classroom with the mixed learning mode to carry out new model construction and teaching design. Through the detailed teaching design of a course for English major, problems are found and solved in teaching practice, aiming at improving the learning effect, improving students' practical ability, analyzing problem-solving ability and self-learning ability.
\end{abstract}

Keywords-flipping classroom; students' practical ability; problem-solving ability; self-learning ability

\section{INTRODUCTION}

"Flipping Classroom" or "Inverted Classroom" refers to re-adjusting the time inside and outside the classroom and transferring the decision-making power of learning from the teacher to the student. In this mode of teaching, valuable time in the classroom, students can focus more on active project-based learning, and jointly study the challenges of localization or globalization and other real-world problems to gain a deeper understanding. Teachers no longer take up time in the classroom to teach information. Students need to complete self-learning before class. They can watch video lectures, listen to podcasts, read enhanced e-books, and discuss with other students on the Internet. Check the materials you need at any time. Teachers can also have more time to communicate with everyone. After class, students independently plan the learning content, learning rhythm, style and way of presenting knowledge. Teachers use teaching methods and collaborative methods to meet the needs of students and promote their individualized learning. The goal is to enable students to obtain more realistic learning through practice. The flipping classroom model is part of the big education movement. It overlaps with the meaning of mixed learning, inquiry learning, and other teaching methods and tools. It is to make learning more flexible and proactive, and to make students more engaged. In the Internet age, students learn a rich online course through the Internet, and don't have to go to the school to receive a teacher's lecture. The Internet, especially the mobile Internet, has spawned a "flipping classroom" teaching model.

To respond to the call for education reform, flipping classroom breaks the limitations of "Teaching First" in the classroom teaching, allowing students to have more experience opportunities, promoting the understanding of knowledge, paying attention to learning methods and learning processes, and promoting students. The ability of independent learning and practical exploration is conducive to the long-term development of students. At the same time, it provides students with a personalized learning space and a variety of learning channels, realizing the sharing of resources, and expanding the amount of teaching information invisibly. The development of activities such as collaboration and communication has made the interaction between teachers and students and students and students more smooth, which can stimulate students' learning motivation to a large extent, improve classroom participation, and realize the true sense of teaching.

\section{ANALYSIS OF RESEARCH STATUS AT HOME AND ABROAD}

Since the emergence of the mixed flipping classroom teaching mode, many experts and scholars at home and abroad have carried out a lot of practice and research on this method from the perspectives of teaching methods and curriculum development.

\section{A. Foreign Research Status}

Foreign research on flipping classroom can be traced back to an academic paper published by Molin Lach, Glen Platt and Michael Tregra in 2000, entitled Reversing the Classroom: Establishing an Inclusive Learning Environment Approach. The article mentions the use of flipped teaching to activate personalized teaching to adapt to the learning style of different students.

However, the name of "Flipped Teaching" and "Differential Teaching" has not been officially introduced in the text. Later, scholars such as J. Wesley Beck and Jeremy Stryer have conducted in-depth research on the flipping classroom. The flipping of the classroom has really surfaced and has laid a solid foundation for the world. In 2012, the Khan Academy received much attention, and the flipping classroom model using micro-courses began to be sought after by global educational researchers.

\section{B. Research State in China}

In China, since the publication of the National Mediumand Long-Term Education Reform and Development Plan (2010-2020) in 2011, China has paid more and more attention to education informatization and has achieved fruitful results in all aspects. China has proposed curriculum reform for more than a decade. We learn from global education and use technology innovation to promote efficient classrooms. Although we have made a lot of efforts, it has had little effect. The flipping classroom is a bottom-up education model reform, initiated by front-line teachers, and truly combines teaching practice. From this point of view, flipping the surface of the 
classroom has brought new ideas to modern classroom teaching and contributed to China's education reform.

The flipping classroom is widely used in the current university course teaching. University study pays more attention to the improvement of students' self-learning ability and cooperative practice ability, and requires students to learn and use knowledge. Flipping the classroom complies with this real need.

At the same time as the flipping of the classroom teaching model, the micro-curriculum has become a hot topic of concern in the education community. Micro-courses can be said to be the main carrier of flipping classrooms. They often use micro-video format as an important resource for students to learn independently before class. Its design, development, teaching application, evaluation, management and experience summary provide the theoretical basis, material resources and the implementation of flipping classroom.

\section{KEY ISSUES TO BE SOLVED}

\section{A. Poor English Foundation and Lack of Interest in Learning}

Many students report that because their English grammar foundation is weak, the amount of words is insufficient, and the English listening foundation is very poor. In addition, many students never have the habit of pre-study. When they use English teaching in class, they can only understand individual words occasionally. Many of the contents are incomprehensible. Although the teacher has repeatedly explained the contents of the textbooks in class, it is basically a day after the teacher' $s$ content is almost forgotten. Moreover, during the review, I found that many words were not, and the grammatical structure could not be analyzed by myself. I didn' t want to touch the textbook again. The long-term superposition of insufficient basic knowledge led to more and more problems. As the teaching progress progressed, the students' shortcomings It seems more and more obvious that once this vicious circle is formed, it will only make the foundation of students worse and worse. Some students' lack of interest in English majors is also one of the factors that affect the effectiveness of learning.

\section{B. Unsuitable Teaching Methods for Students' Needs}

The teaching methods of many college teachers are still continuing the previous forms of teaching. In addition, the knowledge structure is aging, the classroom management method is single, and it is one of the problems reflected by students when they do not know the work.

\section{Weak Students' Self-Learning Awareness}

In the face of the teacher's questions, most of the students will bow their heads and wait for the teacher to name them. If the teachers do not name them, they will rely on those who have good grades or are active in the classroom to answer the teacher's questions. In their concept of ideas, there is very little awareness of the task of taking the initiative to solve problems, and few students actively seek cooperation. In the case of insufficient capacity, the usual measures are to put the problem on hold. Waiting for the teacher to explain, I rarely think spontaneously, and the goal of solving the problem is not the spirit of not giving up.

\section{Unclear Students' Learning Goals}

Many students are studying with the purpose of applying for the teacher's preparation. They just study the teacher's preparation test reference textbooks, and the treatment of many professional courses is just a matter of people. On the other hand, many students put the focus of their studies on the preparation of professional English CET-A or CET-related exams. Many activities in the teaching practice are not involved, and the ability is not exercised and improved.

\section{IMPLEMENTATION OF MIXED FLIPPING CLASSROOM TEACHING MODE IN ClassRoOM TEACHING OF COMPREHENSIVE ENGLISH}

In the teaching experiment, the experimental subjects are the subjects of the previous interview, that is, the 2018 freshmen, the teaching teacher is one person, the reference textbooks used by the students are the same, and the teaching hours are the same.

\section{A. Preparation}

In the process of integrating the mixed flipping classroom teaching mode into the course design process, the teacher should have a certain understanding of the students' overall foundation, learning characteristics and the ability of the current stage, and should also meet the teaching design principles of the mixed flipping classroom teaching mode. In this way, we can better serve the classroom.

\section{1) Questionnaire and Pre-interview}

In order to smoothly introduce the mixed flip classroom teaching mode into teaching, taking "Comprehensive English" as an example, after the teaching content is determined, one class will be selected from the English major 2018 as the experimental class, and the other class will be used as the control class. Classes use mixed flip classroom teaching, and the control class still adopts the split classroom teaching method.

Through interviews and questionnaires to understand the way students like to go to school and to understand whether students have the relevant basic knowledge, as well as attitudes toward group learning and problem teaching, to provide services for the implementation of the hybrid flip classroom teaching mode.

\section{2) Student's Academic Investigation and Analysis}

Students participating in the teaching reform experiment will be assessed by the questionnaire before the application of the mixed flip classroom teaching mode, and will receive pre-interview after the results come out, in order to understand the current classroom participation and relevant knowledge of the students, and affect the learning effect. The factors and attitudes toward group learning and problem teaching lay the foundation for the implementation of the hybrid flip classroom teaching model.

\section{3) Teacher's Own Quality Preparation}

Teachers should constantly improve their professional qualities, and at the same time should have other comprehensive quality skills; teachers should not only teach students knowledge, but also teach and train students' skills; teachers should gradually promote to students' tutors and 
facilitators from simple knowledge instructors. And collaborators change.

\section{4) Student Group Cooperative Learning}

Students in the experimental class are divided into a group mode of 4--5 people, and each group is assigned a group leader who can drive the group's enthusiasm and drive the task. Group-based collaborative learning is an important part of the hybrid flip-school teaching model. Students are grouped according to their interests and strengths based on their own knowledge of the problem, and assume certain responsibilities and obligations within the group

\section{B. Implementation of Mixed flipping classroom Teaching Mode in Classroom Teaching}

The theoretical core of the mixed flip classroom teaching mode is to guide students to find problems and solve problems based on the teaching content and teaching needs, to give the class to the students, to increase the proportion of "learning" in teaching and learning, and to change The teaching method of "equal teaching" is divided into classrooms, which makes students become the main body of the teaching process and enhance students' self-learning consciousness. Through the guidance of the teacher, the students are informed of the answers to the questions in the process of researching and solving the problems.

\section{1) Proposal of the Problem}

The problem is the precondition and basis for the implementation of the hybrid flip classroom teaching mode. In the classroom teaching process, the students' initial understanding of the content learned comes from the reasonable intervention of the micro-courses on the knowledge. On the one hand, the intervention of this kind of problem allows students to have a preliminary understanding of the knowledge to be learned, so that students can understand the knowledge they should master and the content they need to understand in the next learning process, plan their own learning progress, and pass the Master the consolidation of knowledge and deepen the understanding of the nature of the problem. On the other hand, teachers should make a full understanding of the overall quality and personality characteristics of the students in the class, and combine the knowledge to be taught. This requires teachers to fully understand the students and master the teaching materials.

\section{2) Research on the Autonomy of the Problem}

The autonomy inquiry of the problem refers to the students' active inquiry learning through data search, teamwork, communication and summary, and expounding conclusions according to the problem needs in the process of solving the problems raised by the teachers. Autonomy inquiry is a student-centered self-learning process. First of all, students are required to take a proactive approach to the problems raised by the teachers. To solve the fixed problems, the tasks are assigned to each other according to the group's combination, and the personnel who find the data and analyze the data are established. Based on the analysis of the data, the discussion is repeated. And the validity and validity of the conclusions produced by the test. Secondly, the students themselves must find out the existing points of interest through the analysis of the problems. The students' points of interest cross each other and integrate, so that the problem solving process is beneficial to the students' solution itself, because the research on things is only based on interest. On the basis of the above, you can get twice the result with half the effort. Finally, the student's autonomy of the problem is not completely separated from the teacher, and the entire solution is done independently by the student himself or his team. Teachers must play different roles throughout the problem-solving process to assist, motivate, and guide students.

\section{3) Solution of the Problem}

The problem solving of the mixed flipping classroom teaching mode is that after the students discuss the non-structural questions raised by the teachers, they produce inconclusive results through the research of the problems themselves. The output of the results is based on the students' search and self-analysis Based on the production. The final conclusions include the student's own solution to the problem and the teacher's summary.

The student's own solution to the problem is closely related to the student's own learning attitude, observation ability, comprehension ability and language expression ability and teamwork. Whether students' attitudes toward problems are serious and positive determines the amount of time and energy that students spend to solve problems. Some students are willing to spend a lot of time and energy to analyze problems and think seriously, while some students only complete tasks in order to complete tasks, and the results and problems are far less effective than the former; The observation ability is reflected in the students' deep thinking about the questions raised by the teachers, whether the original questions are extended and new problems are developed. These questions help the students to learn and understand the relevant knowledge, and also solve the problems in the real society. The training opportunities are provided; the comprehension ability is expressed by the students' knowledge of the teachers' knowledge. Only when they have a certain understanding and accumulation of the learned knowledge, can students have the direction and method to solve the problem, in order to understand the way Can solve problems better; The ability of language expression can be called communicative ability in the process of solving problems, including the expression of self-knowledge and communication between teams, and the communication with "outsiders" in order to obtain information. It is embodied in the preliminary conclusions drawn by the students after collecting the materials themselves.

Based on this conclusion, the process of communication, dialectic, communication and integration with the group members is of great help to the improvement of students' communicative competence. At the same time, every member of the group has carefully and conscientiously completed their own work, which has a great impact on the output of the results.

The teacher's summary of the problem consists of two parts. One is that the teacher should have the ability and answer to solve the problem when setting up the problem. The second is that when teachers listen to students' opinions, they should think as much as possible from the perspective of students, and timely adjust and supplement their answers to the students. If 
the answers involve more extensive knowledge, teachers should have more Listen to the student's point of view, give affirmation of the student's reasonable opinion, and finally ask questions or introduce new knowledge content for the problem.

\section{Post-interview and Teaching Improvement Measures}

After using the mixed flip classroom teaching mode teaching, in order to understand whether students adapt to the implementation of the hybrid flip classroom teaching mode, and the problems that may exist in the implementation process of the method, the students in the experimental class will be convened to conduct interviews to understand After the students' teaching through the mixed flip classroom teaching mode, the students' effects on knowledge memory and ability improvement provide a reference for the further implementation of the hybrid flip classroom teaching mode.

Finally, in view of the problems found in the interview results after the above teaching, according to the opinions and suggestions put forward by the students in each question interview, several improvements are proposed.

\section{CONCLUSION}

By applying the mixed flipping classroom teaching mode to the teaching of college English majors, it has a great effect on the realization of college English teaching goals and the cultivation of students with the ability to solve practical problems. Students' comprehensive ability can be improved. It can prompt teachers to optimize curriculum design and combine classroom teaching practice with extracurricular tutoring. Finally, the quality of teachers is improved. Teachers are gradually transformed from simple knowledge transferers to student counselors, promoters and collaborators, from heavy knowledge transfer to heavy student skill training, from heavy result education to heavy process learning.

\section{REFERENCES}

[1] The flipping classroom [DB/OL]. (2012-12-1).[2014-4-10]. http://educationnext.org/the flipping classroom.html.

[2] Jonathan Bergmann and Aaron Sams. Flip Tour Classroom[M]. America, International Society for Technology in Education,2012:21 55.

[3] Jianli Jiao. The Influence and Enlightenment of MOOC on Basic Education[J].Primary and secondary school information technology education,2014,(2):10 12.

[4] Xiping Tao. "Flip the Classroom" and "Generate the Course"[J].Primary and secondary school management,2014,(3):58.

[5] Wei Zhao, Hong Wang, Lihui Sun. Design of Flipping Classroom Teaching Model-Based on Analysis of Typical Cases at Home and Abroad[J].Modern educational technology,2013,(8):5 10. 